\title{
AN INVESTIGATION ON THE CHEMICAL AND PHYSICAL PROPERTIES OF GADA AND MUVUR SILICA SAND FOR GLASS MAKING
}

\author{
G. A. Duvuna ${ }^{1,}{ }^{*}$, A. Ayuba ${ }^{2}$, Y. I. Zhigilla ${ }^{3}$ and Y. I. Tashiwa ${ }^{4}$ \\ 1, 2, 3 Department of Mechanical Engineering, Federal PolyteChnic, Mubi, Adamawa State, Nigeria \\ 4, Dept. Of Agric. \& Env. Engr'G ModibBo Adama Univ. Of TeChnology, Yola, Adamawa State, NiGERIA \\ E-mail addresses: ${ }^{1}$ ayubagideon2@gmail.com, ${ }^{2}$ arhyelayuba@gmail.com, ${ }^{3}$ yizhigilla@yahoo.com, \\ 4 yakstashiwa@yahoo.com
}

\begin{abstract}
The suitability of silica sand deposits of Gada and Muvur in Mubi North Local Government Area of Adamawa State, Nigeria for commercial glass production was assessed based on the chemical and physical properties of the silica sand samples collected along the river sides. The test was carried out at National Metallurgical Development Centre (NMDC) Jos. Chemical analysis was carried out using $x$-ray florescence spectrometer (XRFS) and the physical properties such as the particle size, grain morphology and specific gravity examinations were carried out using mechanical shaker (sieving method), electronic microscope to reveal the shape of the samples and the specific gravity testing machine respectively. The results obtained were assessed and compared with the standard requirements for glass making. Gada had the highest percentage of silica content of $81.00 \%$ and Muvur had the lowest percentage of silica content of $79.40 \%$, but all samples are within the acceptable limits for glass making. The iron oxide content in all the samples was found to be high, with highest value of $1.33 \%$ for Muvur and lowest value of $1.28 \%$ for Gada. However, the iron content for all the samples was above $1 \%$ thereby limiting the range of applications to coloured and amber glass manufacturing. The physical properties that is, the grain morphology which was found to be angular with specific gravity of $\mathbf{2 . 5 0}$ for both the samples were found to satisfy the standard requirements for glass making.
\end{abstract}

Keywords: Silica sand, iron oxide, grain morphology, glass, specific gravity, grain fitness number.

\section{INTRODUCTION}

Glass is a solid that possess a non-crystalline (i.e amorphous) structure that exhibits a glass transition when heated towards the liquid state. Silica, soda ash, and lime are the main ingredients in glass making, but many other chemicals can be added to the mixture to create certain properties which make it one of the most versatile of engineering materials $[1,2]$

Silica sand is the primary component of all types of standard and specialty glass. It provides the $\mathrm{SiO}_{2}$ component of glass formulation. The requirement falls into two main groups, namely the degree of purity as indicated by its chemical properties and the physical characteristics of the sand [1].
The presence of iron oxides in silica sands usually results in coloured glass. The iron level is consequently the most critical parameter in determining whether particular sand can be used to make clear or coloured glass [2]. According to Waudby [3], window glass sand may contain $0.1 \%$ to $0.5 \%$ iron oxide $\left(\mathrm{Fe}_{2} \mathrm{O}_{3}\right)$ and dark green bottle glass as much as $2 \%$ to $3 \%$ iron oxide. For colourless glass containers, generally may contain less than $0.035 \%$ $\mathrm{Fe}_{2} \mathrm{O}_{3}$, while flat glass contains between $0.040 \%$ to $0.1 \% \mathrm{Fe}_{2} \mathrm{O}_{3}$ [4].

Glasses may be devised to meet almost any imaginable requirement for many specialized applications. According to Coons and Weeks [5], glass can be made by melting together several

* Corresponding author, tel: +234 - $703-269-2982$ 
minerals at very high temperature. Silica sand by itself can be fused to produce glass, but the temperature at which this can be achieved is about $1700{ }^{\circ} \mathrm{C}$. The addition of sodium carbonate $\left(\mathrm{Na}_{2} \mathrm{CO}_{3}\right)$ known as soda ash, to produce a mixture of $75 \%$ silica $\left(\mathrm{SiO}_{2}\right)$ and $25 \%$ sodium oxide $\left(\mathrm{Na}_{2} \mathrm{O}\right)$, will reduce the temperature of fusion to about $800^{\circ} \mathrm{C}$. However, a glass of this composition is water-soluble and is known as water glass[2; 4].In other to give the glass stability, other chemicals like calcium oxide $(\mathrm{CaO})$, magnesium oxide, aluminum oxide, lead oxide, and barium oxide are needed [2]. Coons and Weeks [5], reported that, most glasses have roughly similar chemical composition of $70 \%-74 \% \mathrm{SiO}_{2}$, $12 \%-16 \% \mathrm{Na}_{2} \mathrm{O}, 5 \%-11 \% \mathrm{CaO}, 1 \%-3 \% \mathrm{MgO}$, $1 \%-3 \% \mathrm{Al}_{2} \mathrm{O}_{3}$, within these limits the composition is varied to suit particular product and production method.

Grain morphology is another physical property that determines the suitability of the sand for glass making. Grain roundness describes the relative sharpness of the grain corners and edges [6]. The visual comparator presented by [7] is one of the widely used devices of grain roundness studies. According to Waudby [3], the roundness of the grain must be angular rather than rounded.

Heavy minerals such as sallimanite, kyanite, andelusite, zircon, spinel, garnet e.t.c represent an inclusion in the finished glass. These particles can survive the glass melting process and comes out as solid inclusion or stone defects. Minerals such as these have their specific gravity greater than 2.65. Thus for any sample whose specific gravity is greater than 2.65, the sample is not desirable for glass making [6].

Suitability assessment of Delichim and Kudzum silica sand in Michika local government area of Adamawa State, Nigeria for glass making was carried out by [8], the result shows that the percentage of the silica sand content was obtained as $76.60 \%$ for Kudzum and $75.90 \%$ for Delichim. The iron content was also obtained as $1.13 \%$ for Delchim and 1.01 for Kudzum. The iron content for the samples was found to be above $1 \%$ thereby limiting their applications to coloured and amber glass production. Also the physical properties were found to satisfy the standard requirement for glass making. Also [9] study the silica sand quality of Yazaram and Mugulbu Deposits in Mubi-North local government area of Adamawa State, Nigeria for glass making, the result shows that the percentage of the silica sand content was obtained as $77.70 \%$ for Mugulbu and $77.60 \%$ for Yazaram. The iron content was also obtained as 1.94 $\%$ for Mugulbu and 1.05 for Yazaram. The iron content for the samples was found to be above $1 \%$ thereby limiting their applications to coloured and amber glass production. Also the physical properties were found to satisfy the standard requirement for glass making. [10], Investigated the Chemical and Physical Properties of Dapchi, Ngala and Gwoza Silica Sand for Glass Making. The result obtained was similar to the one obtained by [ 8 and 9 ]. This paper therefore, intends to assess the physical and chemical properties of two sand samples for glass making.

\section{MATERIALS AND METHOD}

Two samples of silica sand were collected along different stream sides of Mubi-North Local Government of Adamawa State, Nigeria namely Gada and Muvur. Test on chemical and physical properties of the silica sand samples were carried out at the National Metallurgical Development Centre (NMDC) Jos, Plateau State, Nigeria.

\subsection{Sample Preparation}

A British standard method for sampling and analysis of glass- making sand was used [13]. The silica sand samples were first cleared coned and quartered to obtain the representative fraction. The coning and quartering involved pouring the silica sand samples on the flat surface, such that it formed a cone which was divided into four equal parts by using a straight edge. The two alternative quarters were mixed again for further quartering. After which the representative fraction for each sample was later crushed and ground separately to pass through 120 mesh (BS) sieve. This ground silica samples were then used for the chemical analysis. The silica sand samples which were earlier prepared were further ground and sieved to $75 \mu \mathrm{m}$ particle size $4 \mathrm{~g}$ of the sieved samples was intimately mixed with $1 \mathrm{~g}$ of lithium tetraborate binder $\left(\mathrm{Li}_{2} \mathrm{BO}_{4}\right)$ and passed in a mould under a pressure of $10-15$ tonnes/in ${ }^{2}$ to a pellet. The pressed pellets were dried at $1100^{\circ} \mathrm{C}$ for 30 minutes in an oven to get rid of any absorbed moisture and were finally stored in desiccators for analysis. The spectrometer was switched on and allowed to warm up in order to stabilize the optics and the $x$ - ray tube. 


\subsection{Chemical Analysis}

An X - Ray florescence spectrometer (XRFS) was used for the analysis. The samples for the analysis were presented in a homogeneous reproducible form either milled or ground to give a flat surface. It was then calibrated to determine the expected elements or compounds present in the silica sand.

\subsection{Particles Size Analysis}

Dry sieving method was adopted according to [5], and the represented silica sand samples were obtained from the quartered silica sand samples. The samples were first dried in an oven and from each samples, $100 \mathrm{~g}$ was weighed and arranged on a mechanical shaker with the coarsest on top. The machine was operated for 15 minutes. After sieving the samples, the samples were then emptied onto sheet of paper and weighed one after the other, then, the cumulative percentage by weight of the particles passing each sieve was calculated and recorded.

\subsection{Grain Morphology Test}

The shape of the silica sand determined the suitability of the silica sand sample for glass making. The silica sand samples were viewed under electronic microscope to reveal the shape of the samples and their suitability for glass making.

\subsection{Specific Gravity Examination}

The specific gravity was obtained directly from the specific gravity tester. The silica sand samples were introduced into the machine, which automatically carried out the test and displayed the values of the specific gravity digitally on a visual display unit.

\section{RESULTS AND DISCUSSION}

Tables 1, 2 and 3 show the chemical composition, physical properties and the calculated cumulative percentage weight of the silica sand particles passing each sieve aperture of the samples.

The main ingredient for glass making is the silicon oxide or silica and it varies based on the type of glass to be made. The results in Table 1 shows, the chemical contents analyzed for the silica sand samples obtained from the two different rivers. The percentage of the silica sand are $81.0 \%$ for Gada and $79.40 \%$ for Muvur as shown in Table 1, which are high and adequate for glass making [5]. However, the percentage of iron oxide obtained is high and can only be suitable for coloured and amber glass [10]. This is because the iron content is greater than $1 \%$. The percentages of $\mathrm{MgO}$ for the two samples were obtained as 0.18 and 0.19 for Gada and Muvur respectively. The percentages of $\mathrm{CaO}$ obtained for the two samples were 0.20 and 0.20 for Gada and Muvur, respectively. The percentages of $\mathrm{Al}_{2} \mathrm{O}_{3}$ obtained for the two samples were 7.30 and $8.02 \%$ by weight for Gada and Muvur respectively.

The percentages of the entire main ingredients mentioned above ( $\mathrm{MgO}, \mathrm{CaO}$ and $\mathrm{Al}_{2} \mathrm{O}_{3}$ ) obtained in the silica sand samples shown in Table 1 were very low for glass making when compared with the standard percentage composition requirements of 4$5 \%$ of $\mathrm{CaO}$ and $\mathrm{MgO}$ required for sodalime and lead glasses manufacturing $[11,12]$.

The percentages of $\mathrm{Na}_{2} \mathrm{O}$ and $\mathrm{K}_{2} \mathrm{O}$ for the two samples were found to be adequate compared with the standard percentages needed for various glass formulations, as such, the two samples can be used for borosilicate glasses, fibreglasses and to some extent alumina silicate glasses, since the requirement falls within the range of 2-9 percentage by weight [2, 11, 12].

Table 1: Chemical Compositions of the Silica Sand Samples of Gada and Muvur

\begin{tabular}{|c|c|c|c|}
\hline$S / N$ & Composition & $\begin{array}{c}\text { Gada \% } \\
\text { by Weight }\end{array}$ & $\begin{array}{l}\text { Muvur \% } \\
\text { by Weight }\end{array}$ \\
\hline 1 & $\mathrm{Al}_{2} \mathrm{O}_{3}$ & 7.30 & 8.02 \\
\hline 2 & $\mathrm{SiO}_{2}$ & 81.00 & 79.40 \\
\hline 3 & $\mathrm{~K}_{2} \mathrm{O}$ & 7.11 & 7.45 \\
\hline 4 & $\mathrm{CaO}$ & 0.20 & 0.20 \\
\hline 5 & $\mathrm{TiO}_{2}$ & 0.20 & 0.07 \\
\hline 6 & $\mathrm{Cr}_{2} \mathrm{O}_{2}$ & 0.10 & 0.11 \\
\hline 7 & $\mathrm{MnO}$ & 0.04 & 0.02 \\
\hline 8 & $\mathrm{Fe}_{2} \mathrm{O}_{3}$ & 1.28 & 1.33 \\
\hline 9 & $\mathrm{NiO}$ & 0.01 & 0.008 \\
\hline 10 & CUO & 0.05 & 0.05 \\
\hline 11 & $\mathrm{ZnO}$ & ND & ND \\
\hline 12 & $\mathrm{Ga}_{2} \mathrm{O}_{3}$ & ND & 0.05 \\
\hline 13 & SrO & 0.03 & 0.02 \\
\hline 14 & $\mathrm{RB}_{2} \mathrm{O}$ & 0.05 & 0.05 \\
\hline 15 & $\mathrm{BaO}$ & 0.22 & 0.19 \\
\hline 16 & $\mathrm{Nb}_{2} \mathrm{O}_{5}$ & 0.04 & 0.05 \\
\hline 17 & $\mathrm{ZrO}_{2}$ & 0.05 & 0.04 \\
\hline 18 & $\mathrm{Na}_{2} \mathrm{O}$ & 2.01 & 4.03 \\
\hline 19 & $A U$ & 0.02 & 0.02 \\
\hline 20 & $\mathrm{Na}_{2} \mathrm{O}$ & 4.01 & 6.30 \\
\hline 21 & $\mathrm{MgO}$ & 0.18 & 0.19 \\
\hline
\end{tabular}


Grain morphology or shape, specific gravity (SPG) and the grain fitness number (GFN) are the physical properties of silica sand that determine the suitability of silica sand for glass making. The grain morphology for the two samples is angular as shown in Table 2. According to [3], the grain shape or morphology must be angular rather than rounded. Also the specific gravity for the two samples is 2.50. According to [6], silica sand with specific gravity greater than 2.65 is not suitable for glass making. Thus, all the two samples are suitable for glass making when compared with the standard requirements for glass making.

Table 2: Physical Properties of the two Silica Sand Samples Gada and Muvur

\begin{tabular}{llll}
\hline S/N & Composition & Gada & Muvur \\
\hline 1 & $\begin{array}{l}\text { Grain } \\
\text { morphology }\end{array}$ & Angular & Angular \\
2 & $\begin{array}{l}\text { Specific gravity } \\
\text { (SPG) }\end{array}$ & 2.50 & 2.50 \\
3 & $\begin{array}{l}\text { Grain fitness } \\
\text { number (GFN) }\end{array}$ & 23.14 & 16.10 \\
\hline
\end{tabular}

From the results of particle size distribution shown in Table 3. All the two samples were found to be suitable for glass making, because over $90 \%$ of the particle size lie within 15-100 mesh (BS sieve number) [13].

\section{CONCLUSION}

The percentages of silica contents were obtained as $81 \%$ and $79.40 \%$ for Gada and Muvur respectively which is the major glass forming oxide in the two samples were found adequate for glass making because the percentage values lies within the minimum standard requirements of $70 \%$. All the two silica sand samples were found to have the physical properties that met the requirements for the manufacture of glass since the grain morphology were all angular rather than rounded. The percentage of iron oxide in the silica sand samples obtained as $1.28 \%$ and $1.33 \%$ for Gada and Muvur respectively were a little bit higher than $1 \%$, for this reason, it limits its applications to coloured and amber glass production. All the silica sand samples analyzed have additional chemicals or compounds that could be added to improve the quality of the glass produced. Therefore, the silica sand samples investigated are adequate for glass manufacturing and therefore, should be utilized.

\section{REFERENCES}

[1] Raw Materials Research and Development Council (RMRDC), Federal Ministry of Science and Technology, Multi - Disciplinary Task Force report of the Techno- Economy Survey on NonMetallic Mineral Products Sector" $3^{\text {rd }}$ Update Abuja, Nigeria. Pp $14-15$ and 49, 2001.

[2] David M. I. "A Study of Silica Sand Quality and End Uses in Surrey and Kent" www.1st-glass.1stthings.com/articles/glasscolouring.html, accessed on July, 12, 2016.

Table 3: Calculated cumulative percentage weight of the silica sand particles passing each sieve aperture for the two samples (Gada and Muvur)

\begin{tabular}{cccccc}
\hline Sieve Aperture & Mesh Number & Gada \% by weight & Product & Muvur \% by weight & Product \\
\hline 1.40 & 14 & 18.22 & - & 28.34 & - \\
1.00 & 18 & 13.11 & 183.54 & 21.32 & 298.48 \\
0.71 & 25 & 19.29 & 347.22 & 22.32 & 401.76 \\
0.50 & 35 & 21.06 & 526.50 & 15.41 & 385.25 \\
0.355 & 45 & 15.94 & 557.90 & 8.45 & 295.75 \\
0.250 & 60 & 8.55 & 384.75 & 3.07 & 138.15 \\
0.180 & 80 & 2.23 & 133.80 & 0.49 & 29.40 \\
0.125 & 120 & 0.97 & 77.60 & 0.25 & 20.00 \\
0.090 & 170 & 0.25 & 30.00 & 0.08 & 9.60 \\
0.063 & 230 & 0.10 & 17.00 & 0.07 & 11.90 \\
0.063 & -230 & 0.24 & 55.20 & 0.12 & 27.60 \\
& & 99.96 & 2313.51 & 99.92 & 1617.89 \\
\hline
\end{tabular}


[3] Waudby J. E. "A Summary of the Known Deposit of Glass in Nigeria" 1994.

[4] Gillinder, J. "British Geological Survey, Silica Sand Supply Chain. UK" www.mineralszone.com/minerals/silica.html , accessed on Sept. 29, 2017.

[5] Coons, A. T and Weeks, J. D. "British Glass Manufacturers Confederation, 9 Churchill Way, Chapeltown, Sheffield, South Yorkshire, 5352PY. UK" www.britglass.org.uk/types-glass, accessed Sept. 29, 2017.

[6] Tooley F. V. Hand Book of Glass Manufacturing. $2^{\text {nd }}$ Edition Ogden Press, New York, 1987.

[7] Powers M. C. A New Roundness Scale for Sedimentary Particles. John Willey and Sons Inc. New York, 1983.

[8] Ayuba, A. and Duvuna G. A. "Suitability assessment of Delichim and Kudzum silica sand for glass making", Nigerian Journal of Engineering, Vol. 18, Number 1, Sept., 2011, pp. 107-110.
[9] Duvuna G. A. and Ayuba, A. "A study on silica sand quality in Yazaram and Mugulbu Deposits for glass making", Nigerian Journal of Technology, Vol. 34, Number 1, Jan. 2015, pp. 109-112

[10] Sintali I. S and Egbo G. "Investigation on the Chemical and Physical Properties of Dapchi, Ngala and Gwoza Silica Sand for Glass Making" Journal of Engineering and Technology (JET) Vol. 2, No. 2, Bayero University Kano, Nigeria, 2007.

[11] George, R. "Substances Used in the Making of Coloured Glass" www.britglass.org.uk/historyglass, accessed on August. 4, 2017.

[12] Manas C. Science of Engineering Materials. Macmillan Company Publishers India, 1979.

[13] Grimsley, G. P, and Austin, S. P. "British Standard Methods for Sampling and Analysis of Glass-Making Sands" www.Britannica.com, accessed on July, 29, 2016.

[14] "National Metallurgical Development Centre Jos, Plateau State (NMDC)" Nigeria, 2015. 